still present, and the fundi showed the vessels still, very constricted.

On August 19, 1945, his vision had mùch improved, he could read slowly J.8. His vision was still somewhat blue. The fundi showed the vessels to be much more prominent and the fields fairly full to hand movements.

On September 6, 1945, vision much improved. Blue vision had disappeared, but he noticed what he described as blackness in the later afternoon and at night.

Examination of the eyes showed the discs normal, vessels still much constricted, especially the arteries, and the fields showed peripheral constriction.

He was not seen again after this by me, as we had been relieved by the incoming forces.

I was informed that about 40,000 patients had received treatment for malaria, either primary or relapses, in the camp during our period as P's.O.W. This was the only case of quinine amblyopia which occurred.

I think it is interesting to note that the fundi were normal and vessels normal in calibre 48 hours after the onset of the complete blindness, and only later did the constriction appear, also that the discs appeared normal throughout.

I wish to thank the Director-General of Medical Services, for permission to publish this case.

8. Collins Street,

Yours faithfully,

R. Grarme OrR.

Melbourne.

September 25, 1946.

\title{
GRADES OF VISION
}

To the Editors of THE BRITISH JOURNAL OF OPHThalmology.

DEAR SIRS,-Having read the article by $\mathrm{Mr}$. Joseph Minton, and noted the suggested grades of vision, I was wondering if the problem of amblyopia in returned P's.O.W. had been considered at all. Observation of, and discussion with, many of them has suggested to me that the disability for certain occupations may be much beyond what is suggested by the ordinary test for visual acuity.

To begin with the standard of $6 / 6$ is for many people, a low one ; many can easily attain $6 / 5$ and $6 / 4$. Consequently, those who have been reduced from $6 / 4$ to $6 / 6$ or $6 / 9$ by disease are at a disad vantage.

When the lowered visual acuity is caused not by refractive errors 
or interferences in the media, but by areas of scotomata near the fixation point, then the disability may be very much greater. It is not so much a matter of the size of the scotoma, but its position.

If the scotomata lie so that the area affected is to the right of the point looked at (i.e., between the macula and disc) then the patient may have great difficulty in reading fluently, because as his eye travels along the line from left to right, each subsequent word in turn is missing.

If the scotoma is projected so as to lie below the point of gaze, then the patient is inclined to jump down two or more lines when his eyes move to the left to commence a fresh line. Some of these patients had $6 / 5$ and $6 / 4$ vision. Clerical work for these people was difficult, given time they could do it, but not readily.

But when the visual acuity was $6 / 9$ and $6 / 12$ reading became almost impossible. One such patient - an English doctor with 6/12 in each eye-came to the conclusion he would have to give up his occupation as he çould not read, except the print were large, and then only slowly.

As regards - Naval, Mercantile Marine, and Railway employees, dependent upon seeing lights-white or coloured, at night-even $6 / 4$ vision would be dangerous if the scotomata were present.

In support of this, I give the case of an amateur yachtsman with $6 / 5$ vision in the right and left eye, and an amblyopia due to deficiency disease, who lived in the same quarters with me in Singapore overlooking the Johore Straits, who slept poorly at night and used to spend some of his wakeful hours watching an occulting gas buoy with momentary white flash. He remarked to me that he had been puzzled for some days to be unable to find any fixed period for the light, which was about one mile away.

Actually, the light flashed every three seconds but his scotomata, though small, obscured his vision sufficiently to make him quite unreliable. He was under observation for three years and never was his vision less than $6 / 5$ in each eye. He could read small print comfortably.

Though I think it possible that many P's.O.W. thus affected by scotomata may recover somewhat with time, and in addition, may compensate to some extent for their disability, yet it seems to me that special care may have to be taken, lest in certain occupations they be a menace not only to themselves, but also to others.

Yours faithfully,

R. GRAEME ORR.

8. Collins Street,

Melbourne.

September 25, 1946. 